Abstracta Iranica Iranica

Revue bibliographique pour le domaine irano-aryen

Volume 40-41 | 2019

Comptes rendus des publications de 2017-2018

\title{
Lori Khatchadourian. "Pottery typology and craft learning in the Near Eastern Highlands"
}

\section{Sébastien Gondet}

\section{OpenEdition}

1 Journals

\section{Édition électronique}

URL : http://journals.openedition.org/abstractairanica/49326

DOI : 10.4000/abstractairanica.49326

ISBN : 1961-960X

ISSN : 1961-960X

Éditeur :

CNRS (UMR 7528 Mondes iraniens et indiens), Éditions de l'IFRI

Référence électronique

Sébastien Gondet, «Lori Khatchadourian. "Pottery typology and craft learning in the Near Eastern Highlands" ", Abstracta Iranica [En ligne], Volume 40-41 | 2019, document 47, mis en ligne le 30 octobre 2019, consulté le 22 avril 2021. URL : http://journals.openedition.org/abstractairanica/49326 ; DOI : https://doi.org/10.4000/abstractairanica.49326

Ce document a été généré automatiquement le 22 avril 2021.

Tous droits réservés 


\title{
Lori Khatchadourian. "Pottery typology and craft learning in the Near Eastern Highlands"
}

\author{
Sébastien Gondet
}

\section{RÉFÉRENCE}

Lori Khatchadourian. "Pottery typology and craft learning in the Near Eastern

Highlands", Iranica Antiqua, 53, 2018, p. 179-265

1 Cet article constitue une synthèse très complète des évolutions macro-régionales des assemblages de céramiques entre le $7^{\mathrm{e}}$ et le $4^{\mathrm{e}} \mathrm{s}$. avt. J.-C. dans l'ensemble des zones montagneuses situées entre la mer Caspienne et la mer Noire. Il est par ailleurs caractéristique de la démarche que l'A. a décidé d'adopter dans ces dernières publications (cf. son livre Imperial Matter publié en 2016 [ $\mathrm{cr}$ dans AI vol. 37-38-39 (2014-2016) /2018 - R3.2.2/ n 98]) : les données archéologiques sont interprétées à l'aune d'approches et de concepts puisés dans les sciences sociales et cognitives. Pour l'A., les évolutions typologiques de la poterie au cours du $1^{\mathrm{er}}$ millénaire reflètent avant tout les dynamiques anthropologiques internes aux populations du Caucase qui peuvent en partie être expliquées par les bouleversements géopolitiques que connaît alors cette région.

2 L'A. s'appuie sur une analyse précise du corpus de céramiques mis au jour au cours des fouilles, qu'elle a dirigées,du site de Tsaghkahovit situé au centre de l'Arménie et fouillé entre 1998 et 2013. Si les données archéologiques recueillies sur ce site ont déjà fait l'objet de comptes-rendus généraux (voir par exemple Empire in the Everyday [cr dans AI vol. 37-38-39 (2014-2016) /2018 - R3.2.2/ no 90]), on trouvera dans cet article une synthèse détaillée concernant le matériel céramique. Les annexes, qui constituent le dernier tiers de l'article, présentent les descriptions des différents types diagnostiques définis à Tsaghkahovit ainsi que plusieurs planches les illustrant. L'A. s'appuie 
également sur un travail de synthèse d'un ensemble de publications parues en arménien depuis les années 1960 et dont les données et conclusions se retrouvent ici mises à la disposition de la communauté archéologique internationale. Cet article intègre donc quantité de données inédites ou quasi-inédites.

Ce travail de synthèse permet à l'A. de proposer de nouvelles pistes d'interprétation concernant les évolutions typologiques de la céramique à l'échelle macro-régionale. L'histoire de l'Orient ancien impose aux archéologues un cadre chronologique basé sur la succession des grands ensembles politiques. Or comme le démontre bien l'A., à partir des données céramiques du Caucase et celles de Tsaghkahovit en particulier, les cultures matérielles évoluent suivant une autre temporalité surtout lorsqu'il s'agit de productions communes comme la poterie. De manière hétérogène suivant les régions, l'intégration du Caucase dans l'empire et le contact avec d'autres cultures vont se traduire, pour la céramique, par une modification progressive des chaînes opératoires de production alors en vigueur depuis l'Urartu. Ces évolutions se font en fonction des processus d'apprentissage propre aux différentes communautés des potiers et illustrent leur capacité à intégrer pas à pas de nouvelles techniques et à s'extraire d'un modèle de transmission basé sur la reproduction des formes et des techniques traditionnelles héritées de leurs ainés.

Pour la zone du Caucase, on constate en général une stabilité, d'un point de vue technique et typologique, d'une grande partie des assemblages céramiques entre les périodes urartéenne et parthe. Néanmoins, au cours de la période achéménide, l'A. distingue une évolution des productions en trois étapes. On constate d'abord le développement de certains types de céramiques déjà présents dans le Caucase mais dont la production va s'amplifier et les formes peu à peu évoluer (le bol caréné par exemple). Ensuite, au cours de la première moitié de la période achéménide, apparaissent des décors en relief souvent zoomorphiques reproduisant des modèles inspirés de la vaisselle perse de luxe en métal. Enfin, vers la fin de la période achéménide, on constate le développement de la céramique peinte de type "Triangle and Festoon Ware ». Pour définir chacune de ces étapes et leur chronologie, l'A. s'appuie sur de nombreuses comparaisons intra- et inter-régionales.

\section{AUTEURS}

\section{SÉBASTIEN GONDET}

UMR 5133 CNRS-Université de Lyon 